\title{
Challenges in E-Marketing Adoption Among Small Businesses in the Hospitality Industry in Kenya
}

\author{
Charles Owuor Omoga \\ Department of Management Science, School of Business, Economics and Human Resource Development, \\ Alupe University College (A Constituent College of Moi University), Busia, Kenya
}

\begin{abstract}
Small businesses appear to be slow in adopting e-marketing. This study sought to investigate the challenges faced by small businesses in adoption of E-marketing. Specifically, this study sought to determine the relationship between security concerns and adoption of E-marketing and to determine the relationship between perceived cost of e-marketing technology and adoption of E-marketing among small businesses in the hospitality industry in Kenya. A cross sectional survey design was employed. Stratified random sampling method was used to generate the study sample of 115 small businesses, out of which respective owner-managers responded. The study used structured self administered questionnaire to collect primary data while secondary data were collected via relevant publications. Instrument reliability assessment was confirmed using cronchbas alpha while validity was confirmed using content and construct validity testing. The data was analyzed using descriptive and inferential statistics using Partial Least Squares-Structural Equations Modeling implemented in WarpPLS v.5 software. The results show that a negative relationship exists between Security concerns and e-marketing adoption $(\beta=-0.158, p=0.047)$. The results also show a negative relationship between perceived costs and e-marketing adoption $(\beta=-0.260, p=0.002)$. This study recommends the provision Information Technology security systems to prevent spy ware, viruses and hackers and hence improve security of the Internet and provide relatively affordable hosting services for small businesses. The policy makers should also play an active role to ensure that the cyber laws effectively regulate online transactions and protect against virtual theft and hacking. The Vendors of E-marketing applications should also create awareness among small businesses on the advantages of e-marketing and especially on newer technologies like the provision of Software As A Service (SAAS) using cloud technologies. This may reduce the cost of adoption of e-marketing among small businesses that are resource constrained. The Government should also invest in the necessary I.T. infrastructure to allow E- marketing and payment services to be conducted
\end{abstract}

Keywords: E-marketing, Small businesses, Adoption, Information Systems, Cost, and Security concerns

\section{INTRODUCTION}

In the world where technology is always changing, the role of traditional marketing may face challenges. Firms based locally are beginning to experience competition from both small and large firms which hitherto offered no competition; this includes foreign firms that have branches locally and among local firms themselves. This scenario is likely to continue since the technology that can facilitate businesses amongst traders and customers does exist. The Internet being universal in nature has become an important marketing channel for many firms due to its interactive capabilities compared to traditional marketing [1]

Recent developments in Information Technology have led to the emergence of many different technological innovations. Among the many innovations is the Electronic Marketing (E-Marketing) which can be viewed as "a new philosophy and a modern business practice involved with the marketing of goods, services, information and ideas via the Internet and other electronic means" [2]. [3] Explained that any marketing in the Internet should be considered electronic marketing which includes: Electronic marketing (marketing by email);Search marketing (marketing related to the Internet search results; Marketing websites, links and banners; Marketing in social networks.[4]defined it as: "Achieving marketing objectives through applying digital technologies". [5] defined it as: "The use of electronic data and applications for planning and executing the conception, distribution and pricing of ideas, goods and services to create exchanges that satisfy individual and organizational goals". Firms can embrace the use of E-marketing using different channels which bring them closer to clients by offering a wider scope of clients with better communication [6] 


\title{
International Journal of Advanced Research in Computer and Communication Engineering
}

\author{
Vol. 8, Issue 5, May 2019
}

E-marketing has become a growing phenomenon in the world today with companies providing online platforms for the sale and interaction with clients. An online site is where product and inventory information is provided by multiple third parties, whereas transactions are processed by the marketplace operator. Examples of online Market places include, eBay, Bid or Buy, OLX \& Deal Fish. These markets allow convenience to the customer as well entices their decisions through discounts and free delivery services (Post sales services). Online advertising is a large business and is growing rapidly. The embracing of web for $\mathrm{E}$-marketing has been mainly aimed at informing potential clients about their products and services globally in a competitive manner in order to gain a share of online market and lack of offices abroad has led to many firms to use the Internet to market themselves and increase their interaction with customers and hence adjusting their services according to the customers expectation and accommodations services can now be brought to the potential customers monitor through personal computers or smart phones [7] hence, adoption of E-marketing provides facilitation of communication between a firm and potential clients and has led to businesses having a paradigm shift in their marketing strategies to promote their services. There exist many forms of E-marketing which enables business processes to be transacted without physical contact between the business partners. For example, websites enable businesses to view the effectiveness of the advertisement in terms of the people who have visited the website and the exposure time per visitor. Social media marketing as a "connection between brands \& consumers, offer a personal channel and currency for user centered networking and social interaction." [8].The use of social media has become popular due to minimal costs required .It is also simple to use in terms of communication and sharing products with the targeted audience [11].The use of short message service via Mobile phones is yet another form of E-marketing. This is also a popular way of promoting products and services because of the wide reach of potential clients who now own mobile phones and are found in different locations geographically. This method has been viewed as an affordable means of communications especially with bulk SMS services being developed. Mail marketing also helps in terms of posting magazines and newsletters to inform the customers of new products, promotions available through E-mail. These updates strengthen the bond between customers and the businesses.

Small businesses appear to be slow in adopting E-marketing technology to market their products and services [12]. Existing literature examining challenges towards e-marketing adoptions have mainly focused on large businesses and SMEs in general [13] yet small businesses are different from large and medium enterprises in terms of financial constraints, lack of internal IT experts, and a short-range management perspective [14].Therefore 'small businesses as a subgroup warrants unique investigation within SME population' [15].For this reason, this study sought to investigate the challenges facing Emarketing adoption among small businesses in the hospitality industry in Kenya.

The general objective of this study was to investigate the challenges faced by small businesses in adoption of E-marketing

Specifically, this study sought:

i. To determine the relationship between security concerns and adoption of E-marketing among small businesses in the hospitality industry in Kenya

ii. To determine the relationship between perceived cost of e-marketing technology and adoption of E-marketing among small businesses in the hospitality industry in Kenya

This study was subsequently guided by the following research questions:

i. What is the relationship between security concerns and adoption of E-marketing among small businesses in the hospitality industry in Kenya?

ii. What is the relationship between perceived cost of e-marketing and adoption of E-marketing among small businesses in the hospitality industry in Kenya?

\section{LITERATURE REVIEW}

\subsection{Security Concerns and E-marketing adoption}

Security concern is the degree to which the Internet platform is deemed insecure for exchanging data and conducting online transactions. Security concern is an important factor in the context of E-marketing. First, due to the fact that Internet technologies are based on open standards, firms conducting Internet-based businesses experience less control over data standards and access compared to previous legacy systems, such as EDI that is based on private networks and uses less open data standards [16] .

Studies have established that major factors determining the success of Internet based information technology adoption include privacy, security and trust [17]. Security concerns have influenced the selective application of e-marketing in which only electronic mails are exchanged online without corresponding electronic payments [18] .Studies by [18] indicated that 


\title{
International Journal of Advanced Research in Computer and Communication Engineering
}

\author{
Vol. 8, Issue 5, May 2019
}

security concerns had a negative relationship with e-marketing adoption. Similarly studies by [19] showed a negative relationship with security concerns of adopting e-marketing. According to studies by [20] there was a negative correlation between security threat and e-marketing adoption. Hussein in 2010 also found a negative and significant relationship existing between perceived risk and adoption Web-based marketing by SMEs in the hotel industry. Studies by [21] revealed that security was a barrier to adopting e-marketing. The literature review above indicates a general negative trend associating security concerns with e-marketing adoption.

\subsection{Cost and E-marketing adoption}

Financial resource is one of the key determinants during the adoption phase of innovation. Researchers have identified the cost of innovation as a determinant of innovation in many studies for example, [22] in a study of Tanzania SMEs found that $69 \%$ of the respondents agreed that high costs that are associated with e-marketing and this factor limited its application among the studied SMEs. Other results from studies by [21] in Ghana also showed that the majority of respondents $(42.3 \%)$ were of the view that cost impacted negatively on their decision to adopt e-marketing. Other studies by [23] on South African SMEs identified cost of adopting e-marketing to be a significant determinant and had a negative relationship with social media marketing adoption.

\section{METHODOLOGY}

\subsection{Research design}

This research adopted cross sectional survey research design, which borrows substantially from positivist philosophy in research. A cross-sectional survey design was used to gather quantitative data to assess the relationships between the study variables.

\subsection{Study population}

The target population for this study was small businesses in the hotel and hospitality industry in Kisumu County-Kenya. The small businesses in the hospitality industry include small hotel businesses as well as small tour operator businesses. The total target population was 150 small businesses in the hospitality industry.

\subsection{Sampling technique}

This study applied a two stage sampling approach which involved stratified random sampling technique to determine the number of sampling units, in this case small sized hotels and tour operator businesses and then purposive sampling technique which was used to determine the respondents for the study (Managers of small hotels and tour operator businesses in this case).Stratified random sampling was used in this study because there were two groups forming the target population, thus the small hotel businesses and small tour operating businesses. In this study the statistical equations approach was used to determine the sample size. The formula by Yamane (1967) was used to compute the sample size at a $95 \%$ confidence level and $\mathrm{P}=0.05$. Basing on the above formula, the sample size was 103 small hotels and approximately 12 small sized tour operator businesses that formed the total sample size of 115.

\subsection{Research instrument}

This study used a structured self administered survey questionnaire to collect the primary data from the study respondents. A Questionnaire is quantitative tool for data collection. The rationale for using questionnaire is that it is cheaper, flexible and allows for replication of the research procedure thus enhancing validity of research findings.

\section{RESULTS}

\subsection{Analysis of Survey response}

The analysis of survey response was done to determine the number of respondents who did or didn't respond to the survey. Out of a total of 115 respondents, $106(92.17 \%)$ responded to the questionnaire while non respondents were nine in number. To avoid bias [24] recommends response rate of $70 \%$ and above for self administered questionnaires. The response rate was at $97.52 \%$ which was above $70 \%$ hence acceptable for self administered questionnaires such as the one used in this study.

\subsection{Descriptive statistics for the Demographics of the respondents}

From the analysis there were more male respondent than females: 98 males and eight (8) females at $92.45 \%$ and $07.55 \%$ respectively. On the age of the respondents, most respondents were between the ages of $40-49$ years at $64.15 \%$, followed by 30-39 age brackets at $18.87 \%$.The ages between 21-29 recorded a frequency count of four(4) at $3.77 \%$ while the ages 


\section{International Journal of Advanced Research in Computer and Communication Engineering}

Vol. 8, Issue 5, May 2019

between zero to twenty had no respondents at all. On the education level, the survey recorded the most frequent education level for the owner-managers to be university graduates at $67.92 \%$ followed by diploma graduates at $16.04 \%$; and 17 postgraduates at $11.32 \%$.

\subsection{Descriptive statistics for adoption of E-marketing}

The measurement scale for the intention to adopt E-marketing was composed of three items. The respondents were requires to respond to questions on a seven point Likert scale. From the observations in table 4, the mean values and standard deviations were from 4.66 to 5.98 and 1.113 to 1.952 respectively, thus indicating that the respondents generally agreed with the statements.

Table 1: Descriptive statistics for E-marketing adoption

\begin{tabular}{|l|l|l|l|l|l|l|l|l|l|}
\hline Adoption of E-marketing & M.Sc & ST.D & SD\% & SLD\% & DA\% & N\% & A\% & SLA\% & SA\% \\
\hline $\begin{array}{l}\text { 1. My organization intends to adopt } \\
\text { E-marketing }\end{array}$ & 5.98 & 1.113 & 2.8 & 0 & 1.9 & 0 & 8.5 & 60.4 & 26.4 \\
\hline $\begin{array}{l}\text { 2. My organization is likely to take steps at } \\
\text { adopting E-marketing in the future }\end{array}$ & 4.66 & 1.695 & 5.7 & 11.3 & 10.4 & 0 & 38.7 & 24.5 & 9.4 \\
\hline $\begin{array}{l}\text { 3. My organization would highly } \\
\text { recommend the adoption of E-marketing for } \\
\text { other enterprises }\end{array}$ & 5.71 & 1.952 & 4.7 & 1.9 & 9.4 & 0.9 & 56.6 & 18.9 & 7.5 \\
\hline
\end{tabular}

Research data (2018)

The first item measuring E-marketing adoption had most respondents slightly agreeing that their "organization intends to adopt E-marketing" at $60.4 \%$, while in the second item most respondents agreed that their "organization were likely to take steps at adopting E-marketing in the future" at 38.7\%. The third item measuring adoption of e-marketing indicated $56.6 \%$ of the respondents agreed that their "organization would highly recommend the adoption of E-marketing for other enterprises

\subsection{Descriptive statistics for Security concerns measurement items}

The measurement scale for the Security concerns was composed of three items the respondents were requires to respond to questions on a seven point Likert scale. The standard deviation and the mean score are captured in the table 2. From the observations in table 2, the mean values and standard deviations were between 3.28 and 5.95, and 1.296 to 1.966 respectively. For the first item measuring security concerns of participants in the study, 29.5\% slightly disagreed followed by $19 \%$ who strongly disagreed then $16.2 \%$ who disagreed.

Table 2: Security concerns

\begin{tabular}{lllllllllll}
\hline Security concerns statements & M.Sc & ST.D & SD\% & SLD\% & DA\% & N\% & A\% & SLA\% & SA\% \\
\hline $\begin{array}{l}\text { 1.In E-marketing data is safeguarded against } \\
\text { unauthorized changes }\end{array}$ & 4.74 & 1.966 & 19.0 & 29.5 & 16.2 & 4.8 & 12.4 & 8.6 & 9.5 \\
$\begin{array}{l}\text { 2.In E-marketing sensitive data is } \\
\text { protected from those who should not have }\end{array}$ & 5.95 & 1.296 & 1.9 & 14.3 & 40.0 & 1.0 & 38.1 & 2.9 & 1.9 \\
$\begin{array}{l}\text { access to it } \\
\text { 3.E-marketing transaction data can be }\end{array}$ & 3.28 & 1.894 & 16.4 & 4.5 & 22.7 & 7.3 & 24.5 & 12.7 & 7.3 \\
recovered
\end{tabular}

Research data (2018)

Cumulatively, majority of the respondents (64.7\%) disagreed that "in E-marketing data is safeguarded against unauthorized changes or use" as compared total of $21 \%$ who agreed. On the second measurement item for security concerns, most of the respondents (40\%) of the respondents disagreed, followed by $38.1 \%$ who agreed that "in E-marketing, sensitive data is protected from those who should not have access to it" Cumulatively $56.2 \%$ disagreed with the security concerns statement for measurement item two as compared to $42.9 \%$ who agreed. For the third measurement cumulatively, $43.6 \%$ disagreed while $44.5 \%$ agreed that E-marketing transaction data can be recovered if lost .Overally most respondents were concerned of the safety of E- marketing. 


\subsection{Descriptive statistics for perceived cost of e-marketing measurement items}

The measurement scale for the perceived cost latent variable was composed of three items. The respondents were required to respond to questions on a seven point Likert scale. Mean values and standard deviations were from 4.83 in the first item measuring Cost of E-marketing to the third item which had a mean score of 5.53. On average therefore, the mean score was 5.073 thus indicating that the respondents generally agreed with the statements that the cost of e-marketing adoption was perceived to be too high for the business to adopt the e-marketing technologies. For the first item measuring cost of emarketing, $46.2 \%$ indicated that "the cost of E-market adoption would be far greater than the benefits." while for the second item, most respondents slightly agreed that the cost of maintaining E-marketing is/would be too high for our business" at $28.3 \%$ followed by $21.7 \%$ who strongly agreed and $14.2 \%$ who agreed making a total of $64.2 \%$ while $34.9 \%$ disagreed

Table 3: Perceived Cost of E-marketing

\begin{tabular}{llllllllll}
\hline Cost statements & M.Sc & ST.D & SD\% & SLD\% & DA\% & N\% & A\% & SLA\% & SA\% \\
\hline $\begin{array}{l}\text { The cost of E-market adoption would } \\
\text { be far greater than the benefits }\end{array}$ & 5.53 & 1.958 & 9.4 & 4.7 & 2.8 & 0 & 18.9 & 17.9 & 46.2 \\
$\begin{array}{l}\text { The cost of maintain E-marketing } \\
\text { would be too high for our business }\end{array}$ & 4.86 & 1.849 & 4.7 & 5.7 & 24.5 & 0.9 & 14.2 & 28.3 & 21.7 \\
$\begin{array}{l}\text { The cost of training employees to use } \\
\text { E-marketing would be too high for our } \\
\text { business }\end{array}$ & 4.83 & 1.721 & 3.8 & 5.7 & 20.8 & 4.7 & 21.7 & 25.5 & 17.9 \\
\hline
\end{tabular}

Research data (2018)

\subsection{Path analysis using Partial Least Squares -Structural Equation Modeling}

\subsubsection{Outer model assessment (Measurement model)}

The statistical reliability assessment for the latent variable indicators was done by analyzing the 'outer model' (measurement model) which consisted of the latent variable indicators and the paths connecting them to their respective reflective latent variables. In this study, outer model loadings were used in measuring reflective latent variables. Outer loadings represent the relative contribution of the indicator to the definition of its corresponding latent variable [26]

Table 4: Combined Loadings and cross loadings for per indicator

\begin{tabular}{cccc}
\hline Latent variables & Cost & Sec & Adopt \\
\hline Cost-1 & $\mathbf{0 . 6 0 6}$ & -0.752 & -0.029 \\
Cost- 2 & $\mathbf{0 . 8 5 2}$ & 0.002 & 0.046 \\
Cost-3 & $\mathbf{0 . 8 9 7}$ & -0.384 & 0.029 \\
sec-1 & 0.161 & $\mathbf{0 . 9 2 6}$ & -0.048 \\
Sec-2 & 0.015 & $\mathbf{0 . 7 1 0}$ & -0.051 \\
Sec-3 & -0.187 & $\mathbf{0 . 7 2 8}$ & 0.070 \\
Adopt1 & 0.361 & 0.190 & $\mathbf{0 . 8 9 8}$ \\
Adopt2 & -0.372 & -0.386 & $\mathbf{0 . 8 5 1}$ \\
Adopt3 & -0.153 & 0.026 & $\mathbf{0 . 7 8 6}$ \\
\hline
\end{tabular}

Note: Loadings are unrotated and cross-loadings are oblique-rotated, both after separate Kaiser Normalizations. Source: Research data (2018)

\subsubsection{Results of the structural model (Inner model)}

This section presents the findings from the analysis of direct relationships between the independent and the dependent latent variables in the model. Assessment of the structural model (inner model) was done using WarpPLS statistical software v.5. The path analysis involved using an algorithm in which factor scores were estimated by averaging all the indicators associated with the latent variables. P-values were calculated through the process of Resampling. In WarpPLS this was done by using Stable-3 Resampling. Table 5 shows the results of the path analysis. 


\section{International Journal of Advanced Research in Computer and Communication Engineering}

Vol. 8, Issue 5, May 2019

Table 5: Path analysis results (Security concerns/ Cost variables to e-marketing)

\begin{tabular}{llccl}
\hline Latent variables & (beta -estimates) & P-values & S.E & $\begin{array}{l}\text { Significance of path } \\
\text { coefficient } \mathrm{P}<0.05\end{array}$ \\
\hline Security concerns & -0.158 & & & 0.047 \\
Cost & -0.260 & 0.002 & 0.092 & Significant \\
E-marketing Adoption & & & & \\
\hline Rearch data (2018) & & & &
\end{tabular}

Research data (2018)

From table 5, the results indicate that there is a negative relationship between security concerns and adoption of EMarketing $(\beta=-0.158, p=0.047)$. The results indicate also that there is a negative relationship between Perceived costs and adoption of E-Marketing $(\beta=-0.260, \mathrm{p}=0.002)$.

\section{DISCUSSIONS}

\subsection{Discussion on the inferential statistical testing results of the path analysis}

This study examined the relationship between two latent variables namely Security concerns of using technology and Perceived costs of E-marketing .The results indicate that there is a negative relationship between Security concerns and EMarketing adoption $(\beta=-0.158, p=0.047)$. A possible explanation is that the respondents felt that e-marketing though useful was not secure enough for them to conduct business. This is because respondent felt that they had limited options for security of their data. These findings are similar to other studies ([18]; [27] in which Security concerns had negatively influenced the application of technological innovations like e-marketing. [28] Observed that unauthorized access to data would pose grave danger to information security and therefore security of the internet as a platform for engagement of business should be ensured. For the relationship between perceived costs and E-marketing adoption, the results indicate that there is a negative relationship between Perceived costs and E-Marketing adoption $(\beta=-0.260, p=0.002)$. This means that as the cost of E-marketing increases, the chances of adopting E-marketing would also reduce. Small businesses are resources constrained and therefore they are sensitive to pricing of the resources they use which include technological innovations like e-marketing. Studies that have mirrored negative relationship between cost and technological innovation include [23]

\section{CONCLUSION}

From the research findings, this study makes the following conclusions: First, security concerns and intention to adopt Emarketing had a significant negative relationship and this means that security concerns was a significant barrier to the adoption of E-marketing among small businesses. These results indicate that respondents felt that e-marketing was not secure enough for them to conduct business. This is because respondents felt that in E-marketing data is not safeguarded against unauthorized changes or use and that in E-marketing, sensitive data are not protected from those who should not have access to it.

Secondly, the perceived Cost of E-marketing was an area of concern in this study. The study found a negative relationship between perceived cost and intention to adopt E-marketing. This means that as the cost of E-marketing increases, the chances of adopting E-marketing would also reduce. Small businesses are resources constrained and therefore they are sensitive to pricing of the resources they use which include e-marketing.

This study contributes to both theory and practice in several ways. This study has responded to calls to study small businesses separately from Medium and large businesses [13] The results from this study therefore provide an additional perspective of the challenges facing small business adoption of E-marketing adoption within the small business perspective. This study also makes practical contributions to the industry. First, this study illuminates the understanding of e-marketing adoption by small businesss. The insights from the findings in this study may be helpful to vendors and innovators alike in their pursuit toward promoting of E-marketing among small businesss. The study should also prompt the Government policy makers to play an active role to ensure that the cyber laws effectively regulate online transactions and to protect against virtual theft and hacking. To the Internet Service Providers the findings stimulate the need to provide Information Technology security systems to prevent spy ware, viruses and hackers and hence improve security of the Internet and provide relatively affordable hosting services for small businesses. These strategies can stimulate adoption levels positively by the small businesses. 


\title{
International Journal of Advanced Research in Computer and Communication Engineering
}

\author{
Vol. 8, Issue 5, May 2019
}

\section{RECOMMENDATIONS}

This study also recommends the provision of Information Technology security systems by the Internet Service Providers to prevent spy ware, viruses and hackers and hence improve security of the Internet and provide relatively affordable hosting services for small businesses. The government policy makers should also play an active role to ensure that the cyber laws could effectively regulate online transactions and to protect against virtual theft and hacking. The Vendors of E-marketing applications should also create awareness among small businesses on the advantages of e-marketing to small businesses that are resource constrained. The Government should also invest in the necessary I.T. infrastructure to allow E- marketing and payment services to be conducted. E-marketing and especially on newer technologies like the provision of software as a service (SAAS) using cloud technologies. This may reduce the cost of adoption of e-marketing among small business

Although this study has made theoretical and practical contributions to Information System literature, our findings should be interrogated in light of these limitations. First, this study used samples specifically from the hotel and hospitality industry, therefore these study findings should be generalized to other industries with caution and hence, future research ought to be undertaken with populations from other industries as well. Finally, with the cross-sectional nature of the study, direction of causality can only be inferred, therefore longitudinal studies should be undertaken so as to determine the causal links more clearly.

\section{REFERENCES}

[1]. Ngugi, E.(2013) Influence of electronic marketing strategies on the performance of commercial banks in Kenya.(Unpublished MBA Thesis). University Of Nairobi

[2]. Stone, B. (2007). Successful Direct Marketing Methods.8th ed. New York: McGraw-Hill.

[3]. Smith, P. R. \& Chaffey, D. (2005), E-Marketing excellence: at the heart of e-Business, Oxford, UK, Butterworth Heinemann

[4]. Strauss, J., El-Ansary, A. \& Frost, R. (2006).E-Marketing. New Jersey: Pearson Education Inc.

[5]. Shankar, J, Mantrala, M., Kelley, E. \& Rizley.R.(2011).Innovations in Shopper Marketing: Current Insights \& Future Research Iss. Journal of Retailing 1(29)

[6]. Pantano, E. \& Naccarato, G. (2010) Entertainment in Retailing: The Influences of Advanced Technologies. Journal of Retailing and Consumer Services, 17, 200-204.

[7]. Chi, H.(2011). Interactive digital advertising vs. virtual brand community: Exploratory study of user motivation and social media marketing responses in Taiwan. Journal of interactive advertising, 12(1), 44-61

[8]. Shankar, J., Mantrala, M., Kelley, E. \& Rizley.R.(2011).Innovations in Shopper Marketing: Current Insights and Future Research Issues. Journal of Retailing 1(29)

[9]. Acılar, A. \& Karamaşa, C. (2012) Factors Affecting E-Commerce Adoption by Small Hotels: A Comparative Case Study. International Journal of EAdoption, 4(1), 1-10

[10]. Rogers, A.D (2016) Examining Small Business Adoption of Computerized Accounting Systems Using the Technology Acceptance Model

[11]. Alford, P. \& Page, S.J. (2015) Marketing technology for adoption by small business, The Service Industries Journal, 35(11-12), 655-669

[12]. Zhu, K., Kraemer, K.L. \& Xu, S. (2006). The process of innovation assimilation by firms in different countries: A technology diffusion perspective on e-business, Management Science, 52, (10), 1557-15

[13]. Bharati, P., Zhang, C., and Chaudhury, A. (2014), Social Media Assimilation in Firms: Investigating the Roles of Absorptive Capacity and Institutional Pressures, Information Systems Frontiers, 16 (2), 257-272

[14]. Zhu, K. \& Kraemer, K.L. (2005) Post-adoption variations in usage and value of e-business by organizations: Cross-country evidence from the retail industry, Information Systems Research, 16, (1), 61-84.

[15]. Dhankhar \& Singh(2014) E-Marketing in Tourism \& Hospitality Industry: Motivations \& Barriers. International Jour of Techno-Management Research, 2, (2)

[16]. Karanasios, S, \& Burgess, S.(2008). Tourism \& Internet adoption: a developing world perspective. International Journal of Tourism Research, 10(2), 169-182

[17]. Matikiti, R., Afolabi, B. \& Smith, W (2012) Empirical Evidence on the Usage of Internet Marketing in the Hospitality Sector in an Emerging Economy and its Relationship to Profitability. International Review of Social Sciences and Humanities 4(1) 181-197

[18]. Duan, X., Deng, H. \& Corbitt, B. (2010), A critical analysis of e-market adoption in Australian small and medium sized enterprises, Proceeding of Pacific Asia Conference on Information Systems, Taipei, 169.

[19]. Gyamfi, K.A.(2015) Factors affecting the adoption of e-marketing among smes; case study of selected smes in the Kumasi metropolis, Ashanti region.Unpublishes thesis.

[20]. Kazungu, F.P.\& Mchopa (2015) Impediments to adoption of e-marketing by Tanzanian small and medium sized enterprises: An explanatory model International Journal of Economics, Commerce and Management. United Kingdom (3) 6

[21]. Maduku K.D.(2015).Determinants of Mobile Marketing adoption among SMEs in South Africa. Unpublished Ph.D dissertation. University of Johanesburg.retrieved from http//ijdigispace. .uj ac za

[22]. Hair, J. F., Money, A. H., Samouel, P., \& Page, M.(2007).Research Methods for Business. Chrichester, W.S: John Wiley \& Sons, Inc

[23]. Henseler, J., Ringle, C. M., \& Sinkovics, R. R. (2009). The use of partial least squares path modeling in international marketing. Bingley: Emerald Group Publishing Limited.

[24]. Garson, G. D. (2016). Partial Least Squares: Regression \& Structural Equation Models. Asheboro: Statistical Associates Publishing

[25]. Duan, X.(2012). An integrated solution to the adoption of electronic market in Australian small-and-medium sized enterprises; Unpublished Doctoral Thesis.RMIT University

[26]. Stewart, D. \& Pavlou., P. (2002).From consumer response to active consumer: measuring the effectiveness of interactive media. Journal of the academy of marketing science, 30 (4), 376-396. 